\title{
From Giessen to Toulouse: 20 years in domestic animal cytogenetics
}

\author{
I Gustavsson \\ Swedish University of Agricultural Sciences, Department of Animal Breeding and Genetics, \\ S-750 o7 Uppsala 7, Sweden
}

(Proceedings of the 9th European Colloquium on Cytogenetics of Domestic Animals; Toulouse-Auzeville, 10-13 July 1990)

Twenty years have now passed since the first European meeting on cytogenetics of domestic animals was held in Giessen in 1970. I remember that meeting very well because it was one of the first international meetings I attended. A small group of people came together and for most of us it was very exciting - as I hope this meeting is for the young people here - because we knew each other only by name and according to what each had published. Most of those individuals in Europe that we today consider as pioneers in our field participated. The period before our series of meetings started had been stamped by important discoveries in the human field. The correct human chromosome number had been established in 1956 (Tjio and Levan, 1956) and, in 1959, Down's syndrome was associated with trisomy-21 (Lejeune et al, 1959) and Klinefelter's syndrome with the sex chromosome constitution XXY (Jacobs and Strong, 1959). In our field as well, important steps had been taken: $\mathrm{XX} / \mathrm{XY}$ chimerism (Ohno et al, 1962) and autosomal trisomy (Herzog and Höhn, 1968) had been found in cattle; the first reciprocal translocation had been described in pig (Henricson and Bäckström, 1964) and the 1/29 translocation in cattle had been associated with decreased fertility (Gustavsson, 1969).

The initiative for the first European Colloquium was taken - as all of you probably know - by Professor GW Rieck, who retired several years ago. He made, exemplified by communications at several of our colloquia, an immensely valuable contribution of our field, particularly by associating different malformations and diseases with chromosome aberrations. After some irregularity in the beginning, the latest meetings have been held every two years (table I). The approximate number of participants and communications have, since the first meetings, been fairly constant but the number of communications in different subjects has varied. When I look at the people here today, I see many well-known faces. Many people have gone and new people have come, but there is a small nucleus which has attended several meetings. So there are evidently laboratories which have been able to maintain a continuously high level of activity in spite of changes in the economic situation as well as changes of trends in genetics.

If we look at the communications presented over the years, we find that the development of basic cytogenetic information in domestic animals has occupied the 
Table I. Approximate number of participants, total number of communications and number of communications divided among typical subjects, at the previously held European colloquia.

\begin{tabular}{lcccccccc}
\hline & $\begin{array}{c}\text { Giessen } \\
1970\end{array}$ & $\begin{array}{c}\text { Giessen } \\
1975\end{array}$ & $\begin{array}{c}\text { Paris } \\
1977\end{array}$ & $\begin{array}{c}\text { Uppsala } \\
1980\end{array}$ & $\begin{array}{c}\text { Milan- } \\
\text { Gargnano } \\
1982\end{array}$ & $\begin{array}{c}\text { Zürich } \\
1984\end{array}$ & $\begin{array}{c}\text { Warsaw } \\
1986\end{array}$ & $\begin{array}{c}\text { Bristol } \\
1988\end{array}$ \\
\hline $\begin{array}{l}\text { No of } \\
\text { participants }\end{array}$ & 38 & 52 & 59 & 71 & 55 & 68 & $?$ & 53 \\
$\begin{array}{l}\text { No of commu- } \\
\text { nications } \\
\text { banding }\end{array}$ & 20 & 36 & 47 & 66 & 54 & 69 & 60 & $31+$ posters \\
$\begin{array}{l}\text { techniques } \\
\text { clinical } \\
\text { cytogenetics }\end{array}$ & 0 & 8 & 12 & 16 & 4 & 5 & 16 & 8 \\
$\begin{array}{l}1 / 29 \\
\text { in cattle } \\
\text { embryo }\end{array}$ & 1 & 4 & 4 & 8 & 1 & 5 & 4 & 0 \\
$\begin{array}{l}\text { studies } \\
\text { gene }\end{array}$ & 2 & 2 & 3 & 8 & 2 & 3 & 4 & 1 \\
mapping & 0 & 0 & 1 & 4 & 4 & 6 & 5 & 4 \\
\hline
\end{tabular}

participants of the European colloquia to a very large extent. This concerns particularly the identification and detailed description of mitotic chromosomes. The chromosomes of most domestic animals present great problems in identification due to high chromosome numbers and chromosomes of similar morphology. Development has therefore been troublesome sometimes, eliciting many heated discussions. Some of us still remember the controversies about the identification of the X chromosome in pig that started at the standardization meeting held in Reading in 1976, which were accompanied by heated discussions and the slamming of doors. The first European colloquium was hindered by the lack of banding techniques for the description of normal and abnormal karyotypes. However, already at that meeting attempts were being made to overcome the identification problems. One technique, the so-called 'pencil-follower technique' for measuring chromosomes was described in the very first scientific paper (Paufler, 1970). Unofficially at that meeting, KM Hansen from Denmark demonstrated, if I remember correctly, the first Q-banded cattle chromosomes. At the meeting in Giessen in 1975, information about banded chromosomes of several domestic animals was available and was fruitfully collated into agreements on international standards in Reading in 1976 (Proceedings of the First International Conference for the Standardisation of Banded Karyotypes of Domestic Animals, 1980). The information has increased and, in addition to the standard C-, Q-, G-, R- and T-banding techniques (Gustavsson, 1980), which have now been used for several years, the introduction of different fluorochromes and counterstaining techniques (eg, Verma and Babu, 1989) have further simplified 
cytogenetic analysis. High-resolution techniques have been established and even more detailed standards for the domestic animal chromosomes have been agreed to (ISCNDA, 1990). Application of different banding techniques has provided insights into the structure and organization of chromosomes and, with the increasing results on the molecular level, our knowledge can be further increased. We are thus in the position of having a good set of somatic chromosome techniques which enable identification of single normal chromosomes as well as rearranged chromosomes. After this 'chromosome-stretching' era, it is now extremely urgent that we try to use this information more practically. It is therefore with great pleasure that I see many scientists now turning to the gene mapping field. The detailed chromosome information should also be applied to clinical cytogenetics. It is also quite important that we continue to develop our present banding standards into high-resolution ones. In this context, we should not forget the new so-called chromosome painting technique (eg, Pinkel et al, 1989), which will probably be very useful for identification of chromosome segments once chromosome-specific libraries have been established.

Even with new banding techniques, I think, however, that karyotypes such as the bovine ones will continue to pose important analytical problems in the future. A detailed analysis of the karyotype of an individual is very time-consuming and, in my opinion, still to some extent unreliable. In this context, automated or semiautomated analysis will be of great help. I can tell you that even in pigs we sometimes have problems identifying existing aberrations. Caution is therefore to be taken about the reliability of incidences of chromosome aberrations in large samples of animals investigated during a short period of time. To be able to identify deviations, there are several conditions to fulfill, including extensive training of the analyzer and detailed knowledge of single chromosome pairs and their banding patterns. It is very exciting that, by comparing banding patterns of different species, we now have the possibility to discern karyotype evolution. In some groups of animals, like the family Bovidae, karyotype evolution has involved centric fusions, for the most part, while in a group like Equidae there has been more complex karyotype evolution. In this work, the expansion of gene maps will speed up progress. So, one hopes that in the near future we will know how the karyotypes of our domestic animals have evolved and also how karyotype evolution has proceeded in domestic and wild species. This increased knowledge, in turn, can help us make clinical predictions and anticipate the phenotypic outcome of zygotes with chromosomally unbalanced karyotypes.

The number of chromosome aberrations described is still low and our knowledge of their etiology and incidence in different domestic animal populations is very poor. To a very large extent, this is definitely due to the fact that malformed animals, animals with reproductive problems, abortuses, stillborns and so on only rarely come to investigation. I have found that the only way to obtain cytogenetically interesting material is to have good connections with veterinarians, breeders and farmers. This can only be achieved by reiterated information of your work and interests. It is also important that you always show an interest in the problems in the field, even if you think they have no cytogenetic basis. Only a few malformations have been ascribed to abnormal chromosome constitutions. Lately, I have wondered if perhaps we have been too eager to expect dramatic phenotypic changes due to chromosome aberrations. The fact that there are aberrations without extensive 
phenotypic effects was shown by Mayr et al (1985) in trisomic cattle, and also, in our routine analyses in Sweden, by a recent incidental finding of a deletion in a Blonde d'Aquitaine heifer with normal body conformation. We now also have cases of translocations in pigs producing stillborn and even live-born piglets with unbalanced karyotypes, but nevertheless having a fairly normal appearance. Most aberrations have been found in animals with low fertility but, if you look in the literature, you will find that a surprisingly high number has been found more or less incidentally. Such aberrations are centric fusion translocations including $1 / 29$ - already known before this series of colloquia was started - but nevertheless described and discussed at all meetings since then. The incidence of chromosome aberrations to be found in a population is primarily due to the interference of chromosome mutation rate and selection pressure. Very little is known of mutation rate. Of course we have some knowledge from the routine screening of cattle for the presence of 1/29 translocation. In Sweden, at least, trisomies, for example 60,XXY and 60,XYY, appear to occur at a lower incidence in cattle than in humans. It is therefore important that, in the future, we 'map' different populations for chromosome constitution and existing chromosome aberrations. References have been made to human cytogenetics at all of the meetings. We should, of course, consider observations and results and adapt the new techniques to our field, but we have to recognize the big differences between human and domestic animals and also among different domestic animal species. Aberration incidence is such a character.

It is surprising that so little has been reported concerning meiosis and chromosomal polymorphism in domestic animals. Throughout the history of our European colloquia, only few reports have been made on meiosis, other than the work by David Logue (1977) on Robertsonian translocations presented at the colloquium in Paris. Detailed meiotic studies using conventional techniques (eg, Evans et al, 1964) can give information about chiasma localization, segregation and so on. With the synaptonemal complex analysis (Counce and Meyer, 1973), interesting pairing conditions can be evaluated. Doubtfully identified aberrations on the somatic cell level can and should be substantiated definitively with synaptonemal complex analysis, before they are classified as aberrations. Polymorphisms, such as Y-chromosome variations, centric fusion translocations, variable amounts of heterochromatin particularly centromeric, and qualitatively and quantitatively variable NORs (nuclear organizer regions), are common in different domestic species. The extensive variation of centromeric heterochromatin in cattle was pointed out by Di Berardino and coworkers (1980) at the Uppsala meeting which led to later work being done in other species. However, there are no comparative investigations of breeds, populations and so on, and the practical utilization of polymorphisms in paternity tests, genetic relationships between populations and for different experimental purposes has not yet been explored at all. The phenotypic effects, if there are any, should be identified. To the group of polymorphisms should also be added fragile sites, which are still unexplored in domestic animals. Why such phenomena as meiosis and polymorphism have attracted so little interest is difficult to understand. One reason may be that grants are given particularly to projects with a predictable expected economic gain.

Very little is known about mutation rates. Undoubtedly, there are differential mutation pressures due to external and internal factors when different countries, 
geographical areas, species, breeds, etc are compared. The mutation rate can, to some extent, be revealed by studies of chromosome breaks and sister chromatid exchanges. I think this will be a new important area in which a lot of interest will be shown in the future. With the increasing concern for the environment and high-quality food production, it will be necessary to identify the roles of different mutagens in the environment of domestic animals and ascertain their importance. As early as the Giessen meeting in 1975, Lojda and coworkers (1975) reported on such aspects but very few other researchers have carried out similar studies. Personally, I think it is also extremely urgent to clarify the significance of the group of unspecific aberrations called chromosome gaps, achromatic segments, constrictions and so on, which are often mentioned in connection with clinical findings.

In addition to clinical cytogenetics, we can today distinguish two other fields, viz gene mapping and embryo technology, developed during recent years. Although detailed physical gene maps have been available for the human genome, it took a long time before similar maps started to be developed in domestic animals. Good surveys of the development of the field have been given particularly by the Toulouse group at several of our European colloquia (Echard et al, 1982, 1984). In addition to being very time and labor consuming, family studies of chromosome segregation correlated to studies of blood groups, proteins and enzymes most often failed. Somatic hybrid studies gave important results for the domestic pig, while similar work in cattle has appeared more difficult due to chromosome identification problems. The most promising technique until now is in situ hybridization which, by making use of DNA probes, gives more detailed information. Already at the meeting in Uppsala (1980), chromosomally assigned genes were reported and more detailed gene localizations will be described at the present meeting. Of course, we in this field follow what has been described by genetic mapping but, as one of my coworkers will show later, unexpected findings can occur. A more distant approach is genetic transformation by introduction of DNA coding for a known gene into a pronucleus of a fertilized ovum. The material is sometimes integrated into one or more chromosomes. Probably, however, we have to learn more about chromosome structure and organization before genetic transformation can be successfully used as a tool in applied breeding. If you have recently attended general and human genetics meetings, I suppose you have noticed that there is an approach to cytogenetics at the molecular level. I think we also have to go in that direction - it will be profitable for us and cytogenetics is by nature closely linked to molecular genetics. Molecular genetics is the fashion in genetics today but there will be, as maybe some of you fear, no risk of a disappearance of our field. In the future, cytogenetics will continue to be a necessary field - and the cytogeneticists will be a rare group due to the skillfulness and experience needed to achieve good results. We have many problems to study on the cytogenetic level and more detailed information on these problems can be obtained by cooperation with molecular cytogeneticists.

Embryo technology has, to some extent, been developed in conjunction with cytogenetics. By micromanipulation, nuclei or pronuclei can be withdrawn or inserted into ova. In this way, it is possible for instance to produce polyploid embryos, to obtain crossings of distantly related species and to learn about the imprinting phenomenon (eg, Surani and Allen, 1990). Chimeric embryos can be 
produced by fusing different embryos or injecting cells into the inner cell mass of the embryo. Particularly interesting is the culture of pluripotent cells derived from embryos (Notarianni et al, 1990). This work will provide a link to the transfer of foreign genes. The most important practical application of cytogenetics in embryo technology has, however, hitherto been the application of cytogenetic techniques to embryo sexing. For a long time, direct observation of the sex chromosomes in split embryos or a few surgically removed blastomeres was the prevalent technique. However, since it often failed due to the absence of divisions in the collected cells, together with the deleterious effect the manipulation had on the embryo's survival, the technique is now out of mode. Instead, in situ hybridization techniques appeared and several different $\mathrm{Y}$-specific probes became available. Although the in situ techniques now more or less have been replaced by the PCR (polymerase chain reaction) technique, based on molecular amplification of a Y-specific sequence visualized by electrophoresis, in situ hybridization with certain probes can still find application (Schröder et al, 1990).

The development of domestic animal cytogenetics, to a very large extent, has been dependent upon the availability of support funds. It has always been difficult to obtain grants for studying basic phenomena. Most often it has been necessary to offer a possible economic advantage to get grants for a project. Therefore, I personally think that clinical cytogenetics for a long time will remain the backbone of our field due to its importance for veterinary diagnostics and for the eradication of extensively distributed chromosome aberrations causing reduced fertility. There is still, however, an unfamiliarity about the importance of cytogenetics and how to integrate it into new methods of animal production. It is essential that we educate farmers, veterinarians and other people involved in breeding, but it is also necessary that we learn the details of animal breeding.

Although these meetings have been arranged particularly for Europeans working in the field of domestic animal cytogenetics, we have, since the Paris colloquium (1977), been happy to see an increasing number of colleagues from other parts of the world attending our colloquia. At most meetings - indeed as of the first colloquium in Giessen (1970) with Alfred Gropp (1970) - we have also been pleased to enjoy the company of outstanding research workers from other specialized fields. I think that inviting such specialists has been a good idea because it has given us some knowledge of what is going on in other fields. We have obtained new ideas to be applied in our field and the experts invited have also given us sound advice. I think few people here really understand how much a person like Charles E Ford has meant to the development of domestic animal cytogenetics. Other outstanding individuals who have participated are P Burgoyne, A Chandley, K Fredga, J de Grouchy, K Rönningen, M Seabright, TC Smith and C Weissman.

The organization form and the existence of the European cytogenetic colloquia have been discussed on different occasions. Some people have thought that the co-organization of our cytogenetics meetings with other meetings would evoke an increased interest in cytogenetics for people in other fields. The change of the North American cytogenetics meetings, which had previously been subsections of dairy science and animal science meetings, to a more independent state, however, supports the consideration that our present meeting format is still the best. At the first meetings, many communications were given in German but we soon agreed 
to English as the common language. I also remember a communication given in Italian and directly after that someone claimed to give his paper in Austrian. Since most of us do not have English as our maternal language, our vocabulary is often not highly advanced, which can sometimes pose a problem. I have noticed that native English speakers often start using unusual words in discussions. This can be a way to more clearly specify a problem, but can also be a way to prevent people from participating in a discussion. Sometimes communications have been given in American or Australian jargon almost incomprehensible for many of us. Then you start wondering about the scientific content...

It may be a pity that the proceedings are not published in widely circulated journals. However, limited circulation of proceedings has the advantage that more incomplete observations and observations of restricted interest can be presented and discussed in informal ways. If an author thinks his communication is of more extensive interest, he has the possibility to publish his paper in extenso in a widely circulated journal, a possibility many people have used through the years.

It is very important that we always try to maintain an acceptable scientific level in our work - each experiment must have a proper design. There have been tendencies towards failure at a few of the earlier meetings, even with communications given by people considered to be experienced in the field. I think it is very important that we carefully discuss such things and not, due to some sort of courtesy, disregard them. For inexperienced people in our field, it is necessary to learn how to do good work. It is also important that people in other fields recognize us as honest and serious research scientists.

Summarizing this short review, it can be concluded that the development of genetics is, as we all have noted, very fast and we all have problems keeping up with developments. Ten years ago, Hsu (1979) wrote in his book: "Perhaps one of these days biologists will be able to compare two species by reading their gene alignments, base pair by base pair, along each chromosome." At the Uppsala meeting, Rieck (1980) considered this to be a utopia. Nevertheless, we are now close to that point and we can read the base pair sequence, at least for small chromosome segments. The European colloquia have been important milestones in the development of domestic animal cytogenetics, not due to important new discoveries, but because of the fact that they have served as summaries and have been occasions for discussions of problems of mutual interest on both public and personal levels. I hope that this meeting will also have a friendly, familiar atmosphere and provide the setting for fruitful discussions and that good results will follow.

\section{REFERENCES}

Counce SJ, Meyer GF (1973) Differentiation of the synaptonemal complex and the kinetochore in Locusta spermatocytes studied by whole mount electron microscopy. Chromosoma 44, 231-253

Di Berardino D, Iannuzzi L, Di Meo GP, Zacchi RR (1980) Constitutive heterochromatin polymorphism in chromosomes of cattle (Bos taurus). In: Proc 4 th Eur Colloq Cytogenet Domest Anim Uppsala, Sweden (Gustavsson I, ed) 438-457

Echard G, Gellin J, Benne F, Gillois M (1982) Progress in gene mapping of rabbits, cattle and pigs using somatic cell hybridization. In: Proc 5th Eur Colloq Cytogenet Domest Anim Milan-Gargnano, Italy (Succi G, ed) 237-252 
Echard G, Gellin F, Dalens M, Yerle M, Benne F, Hatey F, Gillois M (1984) Progress in rabbit gene mapping. In: Proc 6th Eur Colloq Cytogenet Domest Anim Zurich, Switzerland (Stranzinger $\mathrm{G}$, ed) 347-350

Evans EP, Breckon G, Ford CE (1964) An air-drying method for meiotic preparations from mammalian testes. Cytogenetics 3, 289-294

Gropp A (1970) Chromosomenpathologie in der Humangenetik. In: Proc 1 Eur Kolloq Zytogenet (Chromosomenpathologie) in Vet Med Säugetierkunde, Giessen (Rieck GW, ed) 78-92

Gustavsson I (1969) Cytogenetics, distribution and phenotypic effects of a translocation in Swedish cattle. Hereditas 63, 68-169

Gustavsson I (1980) Banding techniques in chromosome analysis of domestic animals. In: Advances in Veterinary Science and Comparative Medicine 24 (Brandly CA, Cornelius CE, eds) Academic Press, New York, 245-289

Henricson B, Bäckström L (1964) Translocation heterozygosity in a boar. Hereditas 52, 166-170

Herzog A, Höhn H (1968) Autosomale Trisomie bei einem Kalb mit Brachygnathia inferior und Ascites congenitus. Dtsch Tieraerztl Wochenschr 75, 604-606

Hsu TC (1979) Human and Mammalian Cytogenetics. An Historical Perspective. SpringerVerlag, New York

ISCNDA (1990) International System for Cytogenetic Nomenclature of Domestic Animals (Di Berardino D, Hayes H, Fries R, Long S, eds). Cytogenet Cell Genet 53, 65-79

Jacobs PA, Strong JA (1959) A case of human intersexuality having a possible XXY sex determining mechanism. Nature 183, 302-303

Lejeune J, Gautier M, Turpin R (1959) Etudes des chromosomes somatiques de neuf enfants mongoliens. CR Acad Sci (Paris) 248, 1721-1722

Logue D (1977) Meiosis in the domestic ruminants with particular reference to Robertsonian translocations. Ann Génét Sél Anim 9, 493-507

Lodja L, Mikuláš L, Rubeš J (1975) Einige Ergebnisse der Chromosomenuntersuchungen im Rahmen der staatlichen Erbgesundheitskontrolle beim Rind. In: Proc 2 Eur Kolloq Zytogenet (Chromosomenpathologie) in Vet Med Tierzucht Säugetierkunde, Giessen (Rieck GW, ed) 269-276

Mayr B, Krutzler H, Auer H, Schleger W, Sasshofer K, Glawisching E (1985) A viable calf with trisomy 22. Cytogenet Cell Genet 39, 77-79

Notarianni E, Galli C, Laurie S, Moor RM, Evans MJ (1990) Derivation of pluripotent, embryonic cell lines from porcine and ovine blastocysts. In: Proceedings of the 4 th World Congress on Genetics Applied to Livestock Production. Vol XIII. Edinburgh 1990 (Hill WG, Thompson R, Wooliams JA, eds) 58-64

Ohno S, Trujillo J, Stenius C, Christian LC, Teplitz R (1962) Possible germ cell chimeras among newborn dizygotic twin calves (Bos taurus). Cytogenetics 1, 258-265

Paufler S (1970) Chromosomenmessung mit dem Koordinatenmesstisch 'Pencil-Follower' In: Proc 1, Eur Kollog Zytogenet (Chromosomenpathologie) in Vet Med Säugetierkunde Giessen (Rieck GW, ed) 1-7

Pinkel D, Landegent J, Collins C, Fuscoe J, Segraves R, Lucas J, Gray J (1989) Fluorescence in situ hybridization with human chromosome-specific libraries: Detection of trisomy 21 and translocations of chromosome 4. Proc Natl Acad Sci USA 85, 9138-9142 Proceedings of the First International Conference for the Standardisation of Banded Karyotypes of Domestic Animals. (Ford CE, Pollock DL, Gustavsson I, eds). University of Reading, 1976. (1980) Hereditas 92, 145-162

Rieck GW (1980) Development of cytogenetics in Europe. In: Proc 4th Eur Colloq Cytogenet Domest Anim Uppsala, Sweden (Gustavsson I, ed) 7-11 
Schröder A, Miller JR, Thomsen PD, Roschlau K, Avery B, Poulsen PH, Schmidt M, Schwerin M (1990) Sex determination of bovine embryos using the polymerase chain reaction. Arch Tierz 33, 293-299

Surani MA, Allen ND (1990) Genomic imprinting: epigenetic control of gene expression, phenotypic variations and development. In: Proceedings 4 th World Congress on Genetics Applied to Liverstock Production. Vol XIII, Edinburgh 1990 (Hill WG, Thompson R, Wooliams JA, eds) 27-33

Tjio JH, Levan A (1956) The chromosome number of man. Hereditas 42, 1-6

Verma RS, Babu A (1989) Human Chromosomes. Manual of Basic Techniques. Pergamon Press, London 